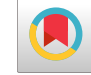

\title{
A Cross-Sectional Study of the Role of HIV/AIDS Knowledge in Risky Sexual Behaviors of Adolescents in Nigeria
} Jennifer R. Pharr, ${ }^{1,2,}$ " Victor Enejoh, ${ }^{3}$ Bertille O. Mavegam, ${ }^{1}$ Ayodotun Olutola, ${ }^{3}$ Haruna Karick, ${ }^{4}$ and Echezona E. Ezeanolue ${ }^{1,2}$

\author{
${ }^{1}$ Department of Environmental and Occupational Health, School of Community Health Sciences, University of Nevada, Las Vegas, Nevada, United States \\ ${ }^{2}$ Healthy Sunrise Foundation, Las Vegas, Nevada, United States \\ ${ }^{3}$ Centre for Clinical Care and Clinical Research, Maitama, Abuja, Nigeria \\ ${ }^{4}$ Department of Psychology, University of Jos, Jos, Plateau State, Nigeria \\ "Corresponding author: Jennifer R. Pharr, Department of Environmental and Occupational Health, School of Community Health Sciences, University of Nevada. Tel: \\ +1-7028952006, E-mail: jennifer.pharr@unlv.edu
}

Received 2016 August 22; Revised 2016 December 22; Accepted 2017 March 06.

\begin{abstract}
Background: Globally, an estimated 4 million of the 35 million people living with HIV are between the ages of 15 and 24 . Nigeria has the second largest burden of HIV worldwide with an estimated 3.2 million individuals living with HIV/AIDS. The prevalence of HIV among adolescents in Nigeria is 3.5\%, which is the highest among countries in West and Central Africa. Although insufficient or a complete lack of knowledge about HIV has been identified as a major barrier to HIV prevention efforts, no study has been conducted to evaluate HIV knowledge, identify deficiencies in knowledge, or examine the relationship between HIV knowledge and risky sexual behaviors (RSB) among adolescents in senior secondary school (high school) in Nigeria.

Objectives: The purpose of this study was to evaluate HIV knowledge, identify deficiencies in knowledge, and examine the relationship between HIV knowledge and RSB among adolescents in senior secondary schools (high schools) in Nigeria.

Patients and Methods: We conducted a cross-sectional survey with a stratified random sample of 361 adolescents from nine senior secondary schools (SS) in Jos Plateau state Nigeria. We used the HIV-KQ-18 survey questionnaire to assess HIV related knowledge and RSB was assessed using the Brief HIV Screener (BHS) questionnaire. Descriptive statistics including mean and standard deviation and multiple linear regression were performed using the SPSS 21. Significance for the statistical test was set at $\mathrm{P}<0.05$.

Results: Overall, 361 participants completed the survey. Forty-seven percent were males and 53\% were females with a mean age of 16.9. HIV knowledge $(\mathrm{t}=-3.3, \mathrm{P}<0.01)$, age $(\mathrm{t}=3.4, \mathrm{P}<0.01)$ and gender $(\mathrm{t}=-2.3, \mathrm{P}<0.01)$ were identified as significant predictors of RSB with female participants having lower RSB scores. An inverse relationship was identified between HIV knowledge and RSB, while a positive relationship existed between RSB and age. Deficiencies in HIV knowledge and misconception about HIV transmission were identified.

Conclusions: Adolescents in this study with higher HIV knowledge had low RSB, indicating the importance of including interventions to increase HIV knowledge in HIV prevention programs. Misconceptions about casual means of HIV transmission need to be clarified, and culturally stigmatizing myths about HIV transmission need to be debunked among adolescents in Nigeria.
\end{abstract}

Keywords: Adolescent, AIDS, HIV, Knowledge, Nigeri, Sexual Behavior

\section{Background}

Globally, an estimated 35 million people were living with HIV in 2013 (1). Children younger than 15 years accounted for 3.2 million, while 4 million individuals living with HIV were adolescents and young adults aged 15-24 (1). Nigeria has an estimated population of 160 million and has the second largest HIV burden with 3.2 million people living with HIV at the end of 2013 (1). The HIV prevalence of $3.5 \%$ among Nigerian adolescents aged 15 to 19 is the highest compared to other countries in West and central Africa. Nigeria also has the highest HIV/AIDS related deaths, ac- counting for $14 \%$ of AIDS deaths globally (1). Most HIV infections in Nigeria are acquired through heterosexual sex, and new cases of HIV are fueled by multiple factors, including a lack of knowledge about HIV and HIV transmission, ineffective treatment for people with HIV, and inadequate access to healthcare (1). United Nations Programme on HIV and AIDS (UNAIDS) found that as many as 7 out of 10 adolescents in Sub-Saharan Africa do not have adequate knowledge about HIV transmission (1). Knowledge and information dissemination are major strategies for combating HIV/AIDS. Partial or insufficient knowledge, not to mention a complete lack of knowledge about HIV among ado-

Copyright ( ) 2017, International Journal of High Risk Behaviors and Addiction. This is an open-access article distributed under the terms of the Creative Commons Attribution-NonCommercial 4.0 International License (http://creativecommons.org/licenses/by-nc/4.0/) which permits copy and redistribute the material just in noncommercial usages, provided the original work is properly cited. 
lescents can be fatal for a population prone to risky sexual behaviors (RSB).

Knowledge is a key component for engaging in preventive behavior. Many behavior theorists posit that a person must have knowledge about a disease and how to prevent the disease in order to engage in prevention behaviors (2-10). Studies from multiple countries other than Nigeria have assessed the relationship between HIV knowledge and sexual behavior in adolescents (11-15). Researchers found that higher HIV knowledge was associated with increased HIV testing, consistent condom use, delayed first sexual intercourse, and a reduced number of sexual partners (11-15). Only one Nigerian study was identified. It examined the impact of knowledge, attitude, and beliefs about HIV/AIDS on sexual behavioral changes among college students and found that knowledge of HIV/AIDS was relatively high among those in college (15). This study also found that males were more likely to have changes in their sexual behaviors (have protected sex) and changes in their dating habits as their knowledge about HIV increased. The authors concluded that HIV|AIDS knowledge was a key theoretical factor in sexual behavior and had a significant impact on sexual behavioral change (15).

Although Nigeria has one of the largest burdens of HIV among adolescents, no study has been conducted to determine HIV knowledge among adolescents to identify deficiencies in knowledge, nor has research been conducted to examine the relationship between HIV knowledge and RSB among Nigerian adolescents.

\section{Objectives}

The purpose of this study was to evaluate HIV knowledge, identify deficiencies in knowledge, and examine the relationship between HIV knowledge and RSB among adolescents in senior secondary schools (high schools) in Nigeria.

\section{Patients and Methods}

\subsection{Setting and Sample}

We employed a cross-sectional design across 9 senior secondary schools (SS) in Jos Plateau state Nigeria. Participants were selected through stratified random sampling, such that in each selected school, two classes were chosen randomly, one each from SS1 and SS2 (grade 10 and 11). Five of the schools were state-owned public schools while 4 were privately owned (missionary/church) schools. Seven (7) were co-educational (mixed) while one (each) was exclusively male or female.
The state ministry of education and the university of Jos, department of psychology ethics committees provided ethical approval for this study. Prior to conducting this study, permissions and consent were obtained from the state ministry of education, school principals, and adolescents. Because the only document linking participants to their data would have been a written consent, it was determined that the best practice to protect participants' privacy and anonymity was verbal consent. Participants provided verbal informed consent to participate in the study. Participation in the study was voluntary and instruments were completed anonymously. No names or any form of identifiers were allowed on the response sheets. Although all students in a class were allowed to participate, they were specifically told at the beginning that they could opt out, could leave the class or alternatively leave the questionnaire blank. Verbal consent was documented on a separate spreadsheet and kept separate from the data. State Ministry of Education, school principals and teachers of specific schools involved were regarded as guardians and gave consent for participation in the study as long as no participant could be identified based on their responses, and they had the liberty of not participating without penalty, or had the option of submitting the response sheet blank without being identified. The consent procedure was approved by the University of Jos, department of psychology and the State Ministry of Education's ethics committees.

Participants were administered the brief HIV knowledge questionnaire and the brief HIV screen questionnaire and asked to provide some basic demographic information (age and gender). Administration of this study was done in class by the investigator. Convenient school times (a period was taken out of a normal school day for the adolescents to complete the questionnaire) were chosen. The schools used this method to avoid disruption in school routine. In all, 450 questionnaires were administered but only 361 were usable for this study. Of the eighty-nine questionnaires omitted, some were not completed properly while others were left blank.

\subsection{Survey Instruments}

The Brief HIV knowledge questionnaire (HIV-KQ-18) is a brief, 18 item self-report questionnaire used to assess HIV related knowledge needed for HIV prevention in high-risk populations (16). Carey and Schroder reported that the HIV KQ-18 has internal consistency and a strong association with the much longer, previously validated 45 item HIV Knowledge Questionnaire (HIV-KQ-45) (16). The developers concluded that the HIV-KQ-18 was stable, sensitive and suitable for use in place of the longer (45 question) questionnaire (16). Carey and Schroder found the HIV KQ-18 to have 
internal consistency across samples (alphas $=0.75$ to 0.89 ) and test-retest stability across several intervals ( $\mathrm{rs}=0.76$ to $0.94)(16)$.

For this study, two locally relevant questions reflective of peculiar local beliefs were added to the HIV-KQ-18 following the recommendation of Peltzer and Promtussananon for a total of 20 items on the HIV Knowledge Questionnaire (17). Peltzer and Promtussananon reported Cronbach's alpha for scale reliability to be 0.76 (17). Scores on the HIV knowledge scale could range from 0 - 20 with 0 equaling no knowledge and 20 equaling excellent knowledge. Response options were true, false and I don't know. Correct answers were coded as 1 and incorrect or "I don't know" as 0 . The scores were summed to give a composite knowledge score that could range from $0-20$. Questions included are listed in Table 1.

The brief HIV screener (BHS) was developed by Gerbert, Bronstone, McPhee, Pantila and Allerton to assess HIV risk and RSB (18). It is a 10-item questionnaire and can be self-administered. Gerbert and colleagues report Kunder-Richardson reliability coefficient for BHS scale to be 0.75 (18). Four additional items adapted from Peltzers and Promtussananon were included because these items were considered to reflect local and cultural knowledge about HIV and sexual behaviors of adolescents in Nigeria (17). This was confirmed and found to be reliable in a pre-test pilot with 20 adolescents from Jos Plateau. The BHS questionnaire includes questions about sexual activity, multiple partners, and unprotected sex (i.e. condom use). The scores were summed to give a composite RSB score that could range from 0 - 14 with a higher score equaling a higher risk.

\subsection{Data Analysis}

Data were analyzed using SPSS 21. Descriptive statistics were computed. Mean and standard deviation (SD) are presented. Brief HIV knowledge questionnaire scores were summed to give a composite knowledge score. Multiple linear regression was used to analyze the relationship between RSB and HIV knowledge, age, and gender. Composite BHS score was the dependent variable for RSB while the summed HIV knowledge score, age, and gender were the independent variables. There were no significant relationships between the independent variables of HIV knowledge, age, and gender, confirming that multicollinearity was not present. Significance for the statistical test was set at 5\%. Additionally, we categorized scores on the Brief HIV Knowledge Questionnaire using the median split with individuals who scored from 0-11 being categorized as having poor HIV knowledge and individuals who scored from 12 to 20 as good HIV knowledge similar to a study by Talwar and Rahman (19).

\section{Results}

\subsection{Demographics}

A total of 361 adolescents completed the survey. Respondents were $46.8 \%$ male (169) and 53.2\% female (192) with a mean age of 16.9 (SD 1.9; range 12 - 24). The mean HIV knowledge score was 11.3 (SD 3.1) and the median was 11 , with a range of 2 -19. The mean BHS was 1.6 (SD 2.8) with a range of $0-14$.

\subsection{HIV Knowledge}

Based on the median split categorization of the Brief HIV Knowledge scores, $51 \%$ of the adolescents had poor HIV knowledge and $49 \%$ had good knowledge. Over $80 \%$ of the adolescents had the correct knowledge about HIV transmission myths and knew that HIV could not be spread by sharing a cup of water with someone who has HIV, using the same toilet seat or swimming pool with an infected person, or through mosquito bites. However, $49 \%$ either believed or were not sure if a person could get HIV through witchcraft or curses. Six questions had a low percentage of correct answers (less than 50\%) (Table 1).

\subsection{Risky Sexual Behavior and HIV Knowledge}

The model generated from multiple linear regression assessing the relationship between RSB and HIV Knowledge was significant $(\mathrm{F}=12.9, \mathrm{P}<0.01)$ with HIV knowledge $(\mathrm{t}=-3.3, \mathrm{P}<0.01)$, age $(\mathrm{t}=3.4, \mathrm{P}<0.01)$ and gender $(\mathrm{t}=-2.3$, $\mathrm{P}<0.01$ ) being significant. The regression equation generated by the multiple linear regression was:

$\mathrm{RSB}=-0.09+-0.15($ HIV knowledge score $)+0.26($ age $)+$ -0.68 (female)

The negative beta coefficient for HIV knowledge shows that as HIV knowledge increased the adolescents' RSB decreased. Female adolescents had lower RSB. RSB increased with increasing age.

\section{Discussion}

In this study, we found that increased knowledge resulted in a reduction in RSB among adolescents. This is consistent with previous studies regarding HIV knowledge and preventive practices among adolescents $(11,12,15)$. Additionally, we found that the HIV knowledge of the majority (51\%) of the adolescents was poor. This is in contrast to Uwalaka and Matsuo study which found the HIV knowledge of college students in Nigeria to be relatively high (15). However, our finding of low HIV knowledge is consistent with other studies of adolescents in Sub-Saharan Africa who are not in college (17). Adolescents in this sample did not have accurate and precise knowledge about 
Table 1. Adolescent HIV Knowledge - Percent of Correct Responses on the Brief HIV Knowledge Questionnaire

\begin{tabular}{|c|c|c|}
\hline & Items & Correct, \% \\
\hline $\mathbf{1}$ & Coughing and sneezing DO NOT spread HIV & 61.5 \\
\hline 2 & A person can get HIV by sharing a cup of water with someone who has HIV & 90.9 \\
\hline 3 & Pulling out the penis before a man climaxes/cums/ejaculates keeps a woman from getting HIV during sex & 40.2 \\
\hline 4 & A woman can get HIV if she has anal sex with a man & 57.1 \\
\hline 5 & Showering, or washing one's genital/private parts, after sex keeps a person from getting HIV during sex & 68.7 \\
\hline 6 & All pregnant women infected with HIV will have babies born with AIDS & 27.7 \\
\hline 7 & People who have been infected with HIV quickly show serious signs of being infected & 67.6 \\
\hline 8 & There is a vaccine that can stop adults from getting HIV & 57.6 \\
\hline 9 & People are likely to get HIV by deep kissing, putting their tongue in their partner's mouth if their partner has HIV & 51.8 \\
\hline 10 & A woman cannot get HIV if she has sex during her period & 64.8 \\
\hline 11 & There is a female condom that can help decrease a woman's chance of getting HIV & 41.0 \\
\hline 12 & A natural skin condom works better against HIV than does a latex condom & 29.9 \\
\hline 13 & A person will NOT get HIV if he/she takes antibiotics & 59.0 \\
\hline 14 & Having sex with more than one partner can increase a person's chance of being infected with HIV & 74.0 \\
\hline 15 & Taking a test for HIV one week after having sex will tell if a person has HIV & 27.4 \\
\hline 16 & A person can get HIV by using the same toilet seat or a swimming pool with a person who has HIV & 81.2 \\
\hline 17 & A person can get HIV from oral sex. (i.e. using the tongue, lips and mouth to give pleasure to someone's sexual organs.) & 43.5 \\
\hline 18 & Using Vaseline or baby oil with condoms lowers the chances of getting HIV & 55.7 \\
\hline 19 & One can get HIV through witchcraft or curses. & 51.0 \\
\hline 20 & HIV can be spread by mosquito bites & 81.2 \\
\hline
\end{tabular}

HIV/AIDS and this sample consisted of adolescents in secondary school who should be a more enlightened and informed segment of adolescents in Nigeria. This would imply that out-of-school rural adolescents with less access to education may have lower knowledge of HIV. Our finding of poor HIV knowledge emphasizes the need for concerted efforts towards HIV education of adolescents in Nigeria.

The present study reveals that adolescents' RSB increased with age. This result is in accordance with that of Berten and Van Rossem who found that older Flemish adolescents were more likely to be sexually active and were less likely to use condoms consistently (12). Moreover, this result is similar to another study, which revealed that older African American adolescents were more likely to be sexually active (11). Our study found that age and HIV knowledge were not significantly correlated, meaning that older adolescents did not have greater HIV knowledge than younger adolescents. This highlights the need for higher levels of HIV education as adolescents matriculate through school, as they become sexually active and at greater risk of participating in RSB.Many of the adolescents in this study lacked detailed information about HIV transmission. For instance, while most (90.9\%) knew that HIV could not be transmitted by sharing a cup, 70\% did not know which type of condom was better for preventing HIV transmission (natural skin or latex), and there were low correct response rates to questions about HIV transmission through oral and anal sex (43\% and 57\%, respectively). Additionally, some adolescents still held to a traditional belief of disease causation that someone could get HIV through witchcraft or curses. This finding is also supported by the work of Uwalaka and Matsuo, who noted that many people in Nigeria believe that diseases are the result of making God angry or are spread by juju priests through curses and witchcraft (15). These findings of miss information about HIV transmission have implications for HIV prevention programs among adolescents in Nigeria. Belief in myths, especially that HIV is caused or can be cured by witchcraft, and that HIV infection is out of their control, may lead to sexual irresponsibility. HIV prevention programs should emphasize that curses/witchcraft do not cause HIV infection (15).

To improve HIV knowledge and reduce RSB, education interventions are necessary. Several methods have proved to be effective for increasing adolescents' HIV knowl- 
edge including interventions based on advocacy, behavior change communication, and peer education and mentoring (20-22). Researchers have found that peer education and mentoring were effective mechanisms for increasing HIV prevention knowledge among adolescents in Nigeria (22-24). Additionally, Arnold and colleague found that including the Family Life and HIV Education (FLHE) program in senior secondary schools was effective in dispelling myths about HIV transmission (25). Efforts are needed to reach rural adolescents who may not be in school. Ofotokon and colleagues found increases in HIV awareness when they used culturally adapted, portable digital-audio technology to provide an HIV education program (26). Culturally appropriate programs that utilize low cost technology may be a viable option to increase HIV knowledge of adolescents in Nigeria.

\subsection{Limitations}

The current study was a cross sectional study conducted in Jos Plateau state Nigeria with adolescents enrolled in 9 senior secondary schools. Because it was cross sectional, causation cannot be determined. Results may not be generalizable to adolescents not enrolled in school or living in other states in Nigeria.

\subsection{Conclusion}

Lack of accurate information about sexual health including HIV transmission may contribute to the high burden of HIV/AIDS among adolescents in Nigeria. Misconceptions about casual means of HIV transmission need to be clarified and culturally stigmatizing myths about HIV transmission need to be debunked.

\section{Acknowledgments}

The authors are grateful to the ministry of education Plateau state, the school principals and teachers who assisted in administering the questionnaire.

\section{Footnotes}

Authors' Contribution: Study concept and design: Victor Enejoh, Ayodotun Olutola and Haruna Karick; acquisition of data: Victor Enejoh, Ayodotun Olutola and Haruna Karick; statistical analysis and interpretation of data: Jennifer Renee Pharr, Bertille Octavie Mavegam; drafting of the manuscript: Jennifer Pharr, Bertille Octavie Mavegam; critical revision of the manuscript for important intellectual content: Echezona E. Ezeanolue, Victor Enejoh.

Conflict of Interest: The authors have no conflicts of interest to report.
Funding/Support: This project was supported in part by the centre for clinical care and clinical research and healthy sunrise foundation. This study was also funded by the Eunice Kennedy Shriver national institute of child health and human development (NICHD), The national institute of mental health (NIMH), and the president's emergency plan for AIDS relief (PEPFAR) under award number R01HD075050 to Echezona E. Ezeanolue.

Role of the Sponsor: The funders had no role in study design, data collection and analysis, decision to publish, or preparation of the manuscript.

\section{References}

1. UNAIDS . Joint United Nations programmes on HIV/AIDS. The Gap Report; 2014.

2. Albarracin D, Durantini MR, Earl A. Empirical and theoretical conclusions of an analysis of outcomes of HIV-prevention interventions. Current Direct Psychol Sci. 2006;15(2):73-8.

3. Albarracin D, Gillette JC, Earl AN, Glasman LR, Durantini MR, Ho MH. A test of major assumptions about behavior change: a comprehensive look at the effects of passive and active HIV-prevention interventions since the beginning of the epidemic. Psychol Bull. 2005;131(6):856-97. doi: 10.1037/0033-2909.131.6.856. [PubMed: 16351327].

4. Bandura A. Understanding and changing health behaviour: From health beliefs to self-regulation. In: Norman P, Abraham C, Conner M, editors. Amsterdam: Harwood Academic; 2000. Health promotion from the perspective of social cognitive theory; p. 299-339.

5. Bandura A. Health promotion from the perspective of social cognitive theory. Psychol Health. 1998;13(4):623-49. doi: 10.1080/08870449808407422.

6. Bandura A. Preventing AIDS: Theories and methods of behavioral interventions. In: DiClemente RJ, Peterson L, editors. CA: Sage Publications; 1994. Social cognitive theory and exercise of control over HIV infection; p. 25-59.

7. Bandura A. Self-efficacy: toward a unifying theory of behavioral change. Psychol Rev. 1977;84(2):191-215. [PubMed: 847061].

8. Glanz K, Rimer BK, Viswanath K. Health behavior and health education: theory, research, and practice. John Wiley \& Sons; 2008.

9. Fishbein M, Yzer MC. Using theory to design effective health behavior interventions. Commun Theory. 2003;13(2):164-83.

10. Fishbein M. The role of theory in HIV prevention. AIDS Care. 2000;12(3):273-8. doi: 10.1080/09540120050042918. [PubMed: 10928203].

11. Swenson RR, Rizzo CJ, Brown LK, Vanable PA, Carey MP, Valois RF. HIV knowledge and its contribution to sexual health behaviors of low-income African American adolescents. J Natl Med Assoc. 2010;102(12):1173-82. [PubMed: 21287898].

12. Berten H, Van Rossem R. Doing worse but knowing better: an exploration of the relationship between HIV/AIDS knowledge and sexual behavior among adolescents in Flemish secondary schools. J Adolesc. 2009;32(5):1303-19. doi: 10.1016/j.adolescence.2008.12.004. [PubMed: 19147217].

13. Tapia-Aguirre V, Arillo-Santillan E, Allen B, Angeles-Llerenas A, Cruz-Valdez A, Lazcano-Ponce E. Associations among condom use, sexual behavior, and knowledge about HIV/AIDS. A study of 13,293 public school students. Arch Med Res. 2004;35(4):334-43. doi: 10.1016/j.arcmed.2004.05.002. [PubMed:15325509].

14. Tenkorang EY, Rajulton F, Maticka-Tyndale E. Perceived risks of HIV/AIDS and first sexual intercourse among youth in Cape Town, 
South Africa. AIDS Behav. 2009;13(2):234-45. doi: 10.1007/s10461-0089470-5. [PubMed: 18846419].

15. Uwalaka E, Matsuo H. Impact of knowledge, attitude, and beliefs about AIDS on sexual behavioral change among college students in Nigeria: the case of the University of Nigeria Nsukka. West Africa Review. 2002;3(2).

16. Carey MP, Schroder KE. Development and psychometric evaluation of the brief HIV Knowledge Questionnaire. AIDS Educ Prev. 2002;14(2):172-82. [PubMed: 12000234].

17. Peltzer K, Promtussananon S. HIV/AIDS knowledge and sexual behavior among junior secondary school students in South Africa.J Social Sci. 2005;1(1):1.

18. Gerbert B, Bronstone A, McPhee S, Pantilat S, Allerton M. Development and testing of an HIV-risk screening instrument for use in health care settings. American J Preventive Med.1998;15(2):103-13. doi: 10.1016/s0749-3797(98)00025-7.

19. Talwar P, Rahman MFBA. Assessment of HIV knowledge among university students using the HIV-KQ-18 scale: A cross-sectional study. South East Asia J Public Health. 2015;5(1):33. doi: 10.3329/seajph.v5i1.24849.

20. Hlavinkova L, Mentel A, Kollarova J, Kristufkova Z. Effectiveness of a prevention campaign on HIV/AIDS knowledge among adolescents in Eastern Slovakia. Int J Public Health. 2014;59(6):905-11. doi: 10.1007/s00038-014-0607-1. [PubMed: 25312012].

21. Mahat G, Scoloveno MA, De Leon T, Frenkel J. Preliminary evidence of an adolescent HIV/AIDS peer education program. J Pedi- atr Nurs. 2008;23(5):358-63. doi: 10.1016/j.pedn.2007.12.007. [PubMed: 18804016].

22. Abu-Saeed MB, Abu-Saeed K. Attitudinal Changes Using Peer Education Training in the Prevention of HIV/AIDS: A Case Study of Youths in North Central Nigeria. Adv Pharm Bull. 2013;3(1):45-50. doi: 10.5681/apb.2013.008. [PubMed: 24312811].

23. Adebayo SB, Gayawan E, Ujuju C, Ankomah A. Modelling geographical variations and determinants of use of modern family planning methods among women of reproductive age in Nigeria. $J$ Biosoc Sci. 2013;45(1):57-77. doi: 10.1017/S0021932012000326. [PubMed: 22739073].

24. Adebayo SB, Fakolade R, Anyanti J, Ekweremadu B, Ladipo O, Ankomah A. Modelling level, trend and geographical variations in stigma and discrimination against people living with HIV/AIDS in Nigeria. SAHARA J. 2011;8(3):115-27. doi: 10.1080/17290376.2011.9724994. [PubMed: 23237726].

25. Arnold R, Maticka-Tyndale E, Tenkorang E, Holland D, Gaspard A, Lug inaah I. Evaluation of school- and community-based HIV prevention interventions with junior secondary school students in Edo State, Nigeria. Afr J Reprod Health. 2012;16(2):103-25. [PubMed: 22916547].

26. Ofotokun I, Binongo JN, Rosenberg ES, Kane M, Ifland R, Lennox JL. Culturally-adapted and audio-technology assisted HIV/AIDS awareness and education program in rural Nigeria: a cohort study. BMC Int Health Hum Rights. 2010;10:2. doi: 10.1186/1472-698X-10-2. [PubMed: 20181073]. 